I Departamento de Antropologia, Universidade do Estado

do Rio de Janeiro (Uerj), Rio de Janeiro, RJ, Brasil

cbrezende65@gmail.com

https://orcid.org/0000-0003-0297-I540

Claudia Barcellos Rezende'

\title{
SENTIDOS DA MATERNIDADE EM NARRATIVAS DE PARTO NO RIO DE JANEIRO' ${ }^{1}$
}

Em cada aniversário seu, a mãe de Milena ligava e falava: "estou lembrando do seu parto! Que parto maravilhoso!”. Ela não se recordava de todos os detalhes, mas dizia que teve que ser parto normal porque em Resende, no estado do Rio de Janeiro, há quase 40 anos, era difícil realizarem cesáreas. Contava que havia começado a sentir umas dores, foi para o hospital, e Milena nasceu "rapidinho". Esse episódio apareceu na narrativa dessa economista de 37 anos sobre seus dois partos - e assim como Milena, outras mulheres estudadas haviam crescido ouvindo suas mães contarem seus nascimentos. ${ }^{2}$ Relatar o parto não é prática restrita a essas mulheres de camadas médias do Rio de Janeiro, mas está presente também em outras sociedades. Como em várias narrativas, aponta questões de agência e subjetividade no modo como se fala a respeito de uma determinada experiência, revelando também concepções pessoais culturalmente específicas. No caso dos relatos de parto, essa prática apresenta também uma vivência corporal que é específica das mulheres, bem como os valores e significados que atravessam cada um destes termos - corpo, vivência, mulher. Concepções de maternidade formam o contexto amplo no qual se inserem essas histórias, seja transformando o parto em rito de passagem para um novo papel social, seja tomando-o como evento existencialmente significativo para a parturiente que já se vê como mãe, permeando assim o modo como a mulher conta seu parto e fala sobre a relação com o feto. Neste artigo, apresento narrativas de mulheres brancas de camadas médias do Rio de Janeiro sobre partos vividos nos últimos cinco anos, com o intuito de analisar as concepções de maternidade nelas expressas. 
Se as narrativas destacam a agência e a subjetividade do narrador, é importante ressaltar que elas se constroem culturalmente, atravessadas por relações de poder. Ortner (2007b: 376) entende a agência como parte da subjetividade, formulada "enquanto modos de percepção, afeto, pensamento, desejo, medo e assim por diante, que animam os sujeitos atuantes" e que são modelados e organizados por formações culturais e sociais. A agência, além de ser constituída por significados culturais de pessoa e do que ela pode fazer, está sempre circunscrita em relações de solidariedade e de poder. Assim, como destaca Ortner (2007a), a agência de projetos é ao mesmo tempo uma agência de poder - a forma como cada sujeito dispõe diferencialmente de poder para realizar suas metas. Com foco no conceito de projeto, Velho (I98I) já havia enfatizado que ele é elaborado a partir de significados e valores culturais e está inserido em campos de possibilidade. Um projeto está sempre referido "a outros projetos e condutas localizáveis no tempo e no espaço" (Velho, I98I: 28), que lhe darão limites.

Recorro a esses conceitos para analisar, neste artigo, como as narrativas de parto destacam as escolhas feitas em torno da maternidade, o que não significa que elas não sejam permeadas e limitadas por valores e relações sociais mais amplas. Nos relatos das mulheres pesquisadas, brancas com idades entre 37 e 46 anos e carreiras profissionais já desenvolvidas, sobressai o investimento afetivo no planejamento do parto, muitos deles realizados a partir de uma perspectiva médica humanizada, reforçando uma visão da maternidade como projeto construído dentro de um campo de possibilidades dado por suas situações socioeconômicas, formas de conjugalidade e valores morais. O modo como o feto enquanto bebê $\hat{e}^{3}$ figura nas narrativas é também significativo, apontando para concepções sobre o vínculo entre mãe e filho, construído e reforçado a partir de uma experiência corporal da gestação e do parto vista como necessária. Assim, discuto como uma forma de subjetividade que valoriza especialmente a corporalidade (Duarte, I999) pode tensionar a agência dessas mulheres.

Essas histórias se distinguem das experiências de parto tal como aconteceram. A ação seletiva do tempo e da memória, argumenta Halbwachs (I990), afeta $o$ ato de recontar um evento, marcado também por preocupações presentes e pelo contexto de expressão. O relato de uma experiência torna-se também uma ocasião em que ela é revivida e recriada, como Bruner (I986) enfatiza. Nesse processo, ela é moldada por formas de expressão socialmente construídas, com unidades organizadas de significados que são acionadas em situações específicas. O modo de elaborar certos temas, com maior ou menor detalhamento ou uso de adjetivos, pode revelar ordens de relevância distintas. Assim, as narrativas dão ênfase ao narrador - a suas emoções, seus pensamentos, motivações e ações (Carson et al., 20I7; Maynes et al., 2008) -, apresentando sempre começo, meio e fim, e estão inseridas em tempo e local particulares (Riessman, I993). 
Examino essas questões a partir de minha pesquisa de campo realizada com mulheres brancas heterossexuais de camadas médias no Rio de Janeiro. ${ }^{4}$ Foram entrevistadas nove mulheres, todas casadas, que realizaram seus partos nos últimos três anos em um contexto de debates mais amplos sobre sua humanização. Têm formação universitária e profissões como economista, administradora, arquiteta, musicista e professora universitária. Dessas mulheres, algumas tiverem partos normais, outras fizeram cesáreas, mas todas desejaram a gravidez. Esses relatos integram uma pesquisa comparativa que inclui também histórias de parto de sete mulheres do mesmo segmento social com idades entre 60 e 70 anos, que tiveram filhos entre I970 e I980, quando começavam a aparecer grupos de preparação para o parto. Nesse conjunto de 16 mulheres, havia dois pares de mãe e filha, mas essa relação não foi critério de seleção das entrevistadas. As mais velhas tiveram em média três filhos, e as mais novas, dois, e todas são usuárias do sistema privado de saúde no Brasil.

Neste artigo, minha análise se detém nas narrativas das mulheres mais jovens, pois é entre elas que aparece uma visão da maternidade como um projeto ancorado na corporalidade. Em alguns momentos, contudo, me refiro às mulheres mais velhas para realçar, por contraste, certas questões. Todas as histórias foram contadas para mim, pesquisadora de geração intermediária às duas pesquisadas. Sou também mãe, fato sabido pela maioria, o que afetou a maneira como descreviam seus partos. ${ }^{5}$ Uma vez que leram e assinaram um termo de consentimento livre, essas mulheres tiveram breve acesso aos objetivos da pesquisa, o que criou um contexto para suas falas e, com relação às mais velhas, trouxe um tom comparativo a seus relatos. Reforço, portanto, que as narrativas que analiso ocorreram em uma relação intersubjetiva específica, em tempo e local particulares.

\section{CONSTRUÇÕES DIVERSAS DA MATERNIDADE}

A maternidade é um laço de parentesco que recebe significados distintos, podendo ser entendido como baseado, por exemplo, no compartilhamento de material genético, na gestação e parto ou na criação e alimentação (Carsten, 2000; Luna, 2002; Pina-Cabral \& Silva, 2013). Pode haver uma só mãe ou mais de uma (Fonseca, 2002) e ser ainda escolhida pela criança (Viegas, 2007). Compara-se com a paternidade, especialmente nas sociedades marcadas por papéis de gêneros demarcados (Carsten, 2004).

Nesse sentido, a maternidade é também um papel social de gênero, revestido de significados e valores cultural e historicamente específicos em torno do laço entre mãe e filho. Badinter (I985) problematizou a ideia de que o amor materno seria natural e instintual. Ao contrário, com base em documentos e livros históricos, sustentou que, durante muito tempo na burguesia francesa, havia uma indiferença materna em relação aos filhos, havendo quando muito predileção por alguns. A construção da maternidade como um vínculo 
afetivo se desenvolveu a partir do século XVIII, associada às transformações na família. Antes, como argumenta Ariès (I98I: 23I), os pais "se ocupavam de suas crianças menos por elas mesmas, pelo apego que lhes tinham, do que pela contribuição que essas crianças podiam trazer à obra comum, ao estabelecimento da família". A nuclearização da família e a delegação da educação das crianças às escolas contribuíram para o surgimento da família sentimental moderna, nos termos de Ariès, e para a ideia de amor materno.

No Brasil, a visão da maternidade como um papel social primordial das mulheres se fortaleceu na década de I920, impulsionada pelos movimentos sanitaristas que articulavam higiene, saúde, educação e nação (Freire, 2008). Se por um lado havia a noção de um instinto materno inerente à condição feminina, aparecia ao mesmo tempo a proposta de que as mulheres precisavam preparar-se para a maternidade. Nessa preparação, os médicos desempenhavam o papel fundamental de transmitir conhecimentos científicos sobre a higiene e alimentação do bebê, para superar práticas tradicionais das amas e comadres associadas a uma cultura antiga e atrasada (Freire, 2008: I60). A puericultura forma-se nesse momento, diferenciando-se da pediatria por enfatizar a educação e a moral vistas como responsabilidades da mãe. Como ressalta Freire (2008), essa nova elaboração da maternidade acompanha assim a reformulação de noções de infância, dos papéis femininos e das relações trabalhistas e sociais.

Além das relações de gênero nos espaços doméstico e público, as diferenças de classe social na sociedade brasileira afetam também o modo como a maternidade é entendida e vivenciada, argumenta Scavone (200I). Para as mulheres de camadas populares, que sempre trabalharam para sustento próprio e da família, a maternidade tende a vir mais cedo e com sentidos variados. Segundo Salem (I980), quando o pai é ausente, o filho pequeno a ser sustentado somente pela mãe pode ser percebido como "fardo" e é por ele que ela se "sacrifica". Como meio de lidar com essas dificuldades, Fonseca (2002) pondera que a circulação rotineira de crianças entre redes familiares cria muitas vezes a percepção de que há mais de uma mãe. Tem havido mudanças entre gerações de mulheres nesses segmentos, como Machado (2009) argumenta. De acordo com sua pesquisa com três gerações, a educação formal passou a ser mais valorizada entre mulheres mais jovens, que já procuram outras fontes de autorrealização além das atividades de dona de casa, esposa e mãe (Machado, 2009: 32I).

Nas camadas médias, a maior inserção no mercado de trabalho pelas mulheres aparece associada ao desejo de alcançar estabilidade financeira antes de ser mãe. De forma semelhante ao estudo intergeracional de Machado, Barros et al. (2009) mostram como, para mulheres jovens desses segmentos, a maternidade divide a atenção com a realização profissional e se apresenta cada vez mais como escolha reflexiva, contrastando com o modo como suas mães e avós a vivenciaram. Para as gerações mais velhas, ser mãe era um papel pouco ques- 
tionado, a ser desempenhado de acordo com códigos preestabelecidos (Almeida, I987). O uso de contraceptivos colabora também para o planejamento e postergação da gravidez, separando sexualidade de reprodução em um corpo objeto de controle de um olhar medicalizado (Foucault, 20 I2). O surgimento de formas de reprodução assistida na década de i 980 colaborou também para que mulheres com problemas para engravidar, com frequência em idade acima dos 35 anos, pudessem gerar e gestar seus filhos - além disso, veio a problematizar a definição de maternidade biológica, nos casos de doação de gametas ou da chamada barriga de aluguel (Cussins, I998; Luna, 2002; Ragoné, I997).

Ainda que se apresente mais como escolha, a maternidade continua associada muitas vezes a uma condição feminina essencializada, ligada ao corpo e à natureza. Os discursos do parto humanizado, disseminados a partir da década de I990, ao criticar o uso frequente de procedimentos médicos vistos como desnecessários, reforçam a visão de um corpo feminino "naturalmente" preparado para parir (Tornquist, 2002). Russo (2018) ressalta como a maternidade, nesse ideário, é apresentada como experiência eminentemente corporal. De forma semelhante, a amamentação vem sendo valorizada em campanhas de saúde pública pelo destaque dado à natureza feminina capaz de amamentar, ato que expressaria um instinto materno de cuidar e dar amor aos filhos (Cadoná \& Strey, 20I4). Essas visões refletem elementos do dispositivo de sensibilidade analisado por Duarte (I999) como parte das sociedades ocidentais modernas. Nele, destaca-se a busca pelo autoaperfeiçoamento contínuo por meio da experiência ancorada na sensibilidade emocional e física. Em particular, o fisicalismo enquanto uma teoria da pessoa considera "a corporalidade humana como dotada de lógica própria, que deve ser descoberta e que tem implicações imediatas sobre a condição humana" (Duarte, I999: 25). Nessa luz, o parto vaginal natural vem se tornando desejo de mulheres de camadas médias e trabalhadoras (Carneiro, 20I5a; Dias, 20I6; Hirsch, 20I5) ancorado a uma ideia de natureza feminina a ser vivenciada de forma mais intensa. ${ }^{6}$ Uma vez que a gestação já vem sendo considerada parte da maternidade, conforme tenho analisado (Rezende, 20I5a, 20I5b), esse evento deixa de ser um rito de passagem, como em outras gerações (Almeida, I987; Salem, 2007), para ser valorizado enquanto experiência física e emocional da mulher.

É importante ressaltar que as escolhas em torno da maternidade acontecem em um contexto de medicalização da gestação e do parto, que se constitui em um conjunto de práticas, saberes e poderes em torno do corpo (Foucault, 20I2; Rabinow \& Rose, 2006).7 Se, como disse acima, as novas tecnologias reprodutivas abrem novas possibilidades para mulheres mais velhas terem filhos, a gravidez passa a ser vivenciada enquanto um estado corporal que deve ser cuidado por profissionais de saúde, por meio de consultas e exames regulares. O parto hospitalar, mesmo que em formatos humanizados, ainda é mais comum em meio urbano. O olhar normalizador da medicina discutido por Foucault 
permeia, portanto, essas experiências, mesmo entre aqueles que compartilham o ideário humanizado do parto. As negociações com médicos obstetras, hospitais e planos de saúde constituem os contextos e os campos de possibilidade nos quais se inserem os projetos de maternidade das mulheres de camadas médias.

As narrativas das mulheres jovens entrevistadas destacam uma visão da maternidade como projeto, que envolve uma série de escolhas feitas com o marido e às vezes com a família, e negociadas com os médicos. A gravidez e o parto desejado foram planejados pelo casal após algum tempo de casamento, quando as mulheres já tinham mais de 30 anos de idade. Predominou nos relatos o uso da primeira pessoa do plural não só para falar da gestação, mas também do parto, do qual os maridos participaram ativamente. Para tanto, prepararam-se com informações de livros e sites de internet ou frequentando grupos de gestantes. A escolha do obstetra foi uma questão importante - ele foi selecionado a partir de recomendações de parentes e amigos e, em muitos casos, de sua reputação como favorável ao parto vaginal, mesmo que não aceitasse plano de saúde, como foi o caso dos que atenderam algumas entrevistadas. Ainda que a referência às mães tenha sido mais frequente em suas histórias, as escolhas médicas muitas vezes se contrapunham às opiniões maternas, tendo sido feitas pelo casal. Vários aspectos dos discursos em torno do parto humanizado figuram em seus relatos, e muitas tiveram partos com médicos adeptos desse ideário, alguns sem anestesia ou episiotomia, tendo tudo sido conversado e negociado com elas. Todas tiveram o parto escolhido - algumas fizeram cesárea na primeira gravidez e depois realizaram parto vaginal. As dificuldades ou problemas mencionados resultaram de imprevistos na evolução do trabalho de parto, do comportamento médico, que teria sido mais crítico ou menos acolhedor, ou da equipe de profissionais do hospital, por contas de regras preestabelecidas. Com exceção de uma mulher, que preferiu não saber o sexo do bebê, as demais já sabiam se esperavam menino ou menina, nomeados desde o início da gestação e mencionados pelo nome ao longo das narrativas.

Como contraste, para as entrevistadas mais velhas, as primeiras gestações foram desejadas, mas em geral não esperadas, vindo quando tinham $20 \mathrm{e}$ poucos anos, eram recém-casadas e estavam cursando faculdade. Seus maridos acompanharam-nas no hospital, mas poucos assistiram ao nascimento dos filhos. O relato das gestações também não os inclui. ${ }^{8}$ Suas mães aparecem pouco nas narrativas, às vezes entrando em cena depois do parto para ajudar no cuidado dos bebês. São narrativas em sua maioria na primeira pessoa do singular, remetida a experiências vividas de forma mais isolada. Nas primeiras gestações, todas quiseram ter parto vaginal, considerado o "parto normal" na época. Entre as sete mulheres entrevistadas, apenas duas buscaram alguma forma de preparo para o parto - uma pela leitura de livros, e outra frequentando um grupo de gestantes, prática que começava a surgir no Rio de Janeiro. Muitas contaram 
experiências complicadas, com dificuldades ou mudanças no tipo de parto, por conta de decisões do obstetra feitas sem as consultar, indicando assim uma relação assimétrica com o médico. A indução do trabalho de parto por meio de ocitocina sintética, a administração de anestesia geral e o recurso a fórceps ou extrator a vácuo foram medidas usadas e desaprovadas, levando muitas a mudar de obstetra na gestação seguinte. O parto foi o momento também em que "conheceram" o bebê, cujo sexo a maioria desconhecia, não tendo sido nomeado até então. Durante os relatos, o bebê não foi mencionado pelo nome quando falavam sobre a gravidez e o parto; só depois de nascidos. Para elas, a maternidade se iniciou com esse evento e, mesmo assim, só se consolidou subjetivamente algum tempo após o nascimento do primeiro filho.

Aprofundo a seguir os sentidos da maternidade das mulheres jovens pela análise da relação com o bebê e do planejamento do parto, destacando respectivamente os modos de pensar o laço de parentesco e o papel social, em dois relatos específicos. Cada depoimento é exemplar no sentido de trazer à tona, de forma clara, noções e valores em torno desses temas. São ao mesmo tempo singulares, como foram todas as histórias.

\section{O FETO COMO BEBÊ E FILHO}

Júlia e seu marido planejaram engravidar ao voltar para o Brasil, depois de morar alguns anos na Europa. Apesar de ter emagrecido por conta dos enjoos, ela achou sua gestação boa e tranquila, "bem conectada". Queria muito um parto de cócoras e se preparou com ioga e um método inglês de respiração. Por conta desse desejo, trocou de obstetra no meio da gestação, pois percebeu que sua médica preferia fazer cesáreas. Seu trabalho de parto foi muito rápido - logo após sua bolsa estourar, as contrações vieram muito fortes e rápidas, mas o bebê continuava alto. Teve problemas com a equipe médica, que ela qualificou como "asquerosa", porque insistia em dar anestesia quando ela não queria ou em fazer episiotomia quando ela achava desnecessária. Tinha preparado música e luz especiais para o parto, mas não conseguiu criar o ambiente que queria na sala de parto por conta das interações com os médicos. Atribuiu ao estresse com a equipe o fato de o bebê ter demorado a descer. Depois de muita dor e cansaço, pediu anestesia, e o bebê desceu. O médico disse para ela fazer força, o que não era bom segundo a técnica de respiração com a qual ela se preparara. Na hora ela sentiu que, se não acatasse seu médico, seu filho não iria nascer. Depois ele insistiu que era preciso fazer o corte do períneo, senão o bebê não conseguiria passar. Júlia cedeu, e Pedro nasceu. Sua recuperação pós-parto teve complicações sérias por conta dessa episiotomia, que ela considera ter sido malfeita. Apesar de ter tido febre durante um mês e ter feito pequenas cirurgias ao longo de um ano, tinha muito leite para amamentar e Pedro foi um bebê "gigantesco". Júlia fala que a relação que desenvolveu com seu bebê na gravidez foi fundamental para ajudá-la a não ter depressão pós-parto com todas as dificuldades de saúde 
que enfrentou. Desde a gravidez se sentia conectada a Pedro - estabeleceu um diálogo com ele, cantava para ele suas músicas e sentiu que o conhecia desde a barriga.

Como outras mulheres mais jovens, Julia narra como planejou sua gravidez e seu parto, preparando-se por meio da ioga e de técnicas de respiração. Conta também como buscou um obstetra com reputação de fazer parto normal e, como algumas, teve queixas sobre o comportamento da equipe médica durante o parto. Seu relato, contudo, foi o mais dramático por conta das dificuldades que teve no pós-parto, apontando para suspeitas de erro médico na episiotomia, que causara a infecção no pós-parto e exigira mais de uma cirurgia nos meses seguintes. A experiência tinha sido traumática a ponto de ela não saber se teria coragem de enfrentar um segundo parto. O contraste em sua história estava na figura pacífica de seu bebê, que era calmo e mamava bem. Segundo ela, foi sua relação com ele, existente desde a gestação, que a sustentou emocionalmente durante sua recuperação.

Julia não foi a única a falar de uma relação com o bebê estabelecida já desde a gravidez. Entre as mulheres mais jovens, o feto era sempre tratado como bebê e referido pelo nome. Nesse sentido, o contraste com as histórias das mulheres mais velhas é significativo, havendo, nas narrativas do parto, poucas referências ao bebê e, quando aparecem, são vagas - a criança, o bebê. Como naquela época a ultrassonografia obstétrica começava a se desenvolver e ainda não era uma prática disseminada de cuidado pré-natal, a maioria dessas mulheres não sabia o sexo do bebê, que só recebeu nome depois de nascer. Ressalto aqui que, como são relatos retrospectivos, os nomes dos bebês poderiam ter sido mencionados durante suas narrativas sobre a gestação e o parto, mas não o foram. Como disseram algumas entrevistadas, o parto havia sido o momento em que "conheceram" seus bebês.

Julia menciona, em sua descrição do parto, como Pedro não conseguia descer. A nomeação do bebê contribui para sua construção como pessoa, como já discuti em outro artigo (Rezende, 20I5b). Não só seu primeiro nome costuma ser escolhido cedo na gestação, como também seus sobrenomes, já o inserindo em uma rede de parentesco. Assim nomeado, o bebê é foco de conversas e música e, na história de Julia, é percebido como sujeito que faz parte de um diálogo. A ideia de que é o bebê que 'resolvia' nascer em determinado dia ou finalmente 'descer' era comum entre essas mulheres, reforçando uma concepção de sujeito ativo em seu próprio nascimento.

Além de sua percepção como pessoa, o bebê já era frequentemente referido como "filho". Nesse sentido, a concepção e gestação do bebê construíam o vínculo de parentesco entre mãe e filho não só na narrativa de Júlia, mas também na das demais. Esse tratamento refletia e reforçava a autopercepção das mulheres como mães desde a gravidez, em contraste com as mulheres mais velhas, para quem a maternidade se desenvolvia apenas depois do parto. Júlia 
enfatiza que já 'conhecia' seu filho quando ele nasceu. Como ela repetiu em vários momentos, a conexão com seu filho, estabelecida desde a gestação, deu a ela esteio emocional para lidar com seus problemas de saúde no pós-parto. Aparece aqui de forma implícita a ideia de amor sacrificial da mãe (Mayblin 20 I I), traço que remeteria à ontologia cristã, aproximando esse sentimento ao amor divino. ${ }^{9}$ Júlia afirma que suas graves dificuldades físicas não a impediam de sustentar no corpo o cuidado do filho por meio do leite abundante. Essa noção permeia também a narrativa de Milena, que discuto a seguir.

\section{A MATERNIDADE PLENA NO PARTO}

Milena conta que sempre gostou de planejar tudo. Funcionária pública formada em economia, optou por fazer um concurso público já pensando na estabilidade para quando se tornasse mãe. Sempre quis ter filho. Casada com um homem com um filho do primeiro casamento e que queria muito ter uma menina enquanto ela ainda se sentia insegura por conta das "preocupações de mãe", eles arriscaram, e ela engravidou logo, aos 34 anos. "Uma gestação muito amada, muito querida", que ela sentiu assim que houve a fecundação. Teve uma gravidez tranquila, cantando sempre para seu bebê. Mas ela morria de medo de hospital e não saber quando o bebê ia nascer a fez escolher uma cesárea. Milena fala que o parto de sua filha foi lindo, pois a equipe respeitou a participação de seu marido, que fotografou algumas coisas, e a anestesia e a recuperação foram boas e tranquilas. O nascimento de Maria deu-lhe mais maturidade para lidar com seus medos de doença, de hospital, de ver sangue. Ao mesmo tempo, sentiu um "vácuo... como mulher; tinha me faltado vivenciar alguma coisa, a questão do trabalho de parto, as dores do parto, a espera". Assim, quando engravidou pela segunda vez, aos 36 anos, quis um "parto normal humanizado". Leu bastante, procurou uma obstetra adepta desse tipo de procedimento e teve também o acompanhamento de uma enfermeira obstétrica. Preparou-se mais "para ser mãe: eu vivenciei mais essa relação da maternidade". Entrou em trabalho de parto e contou como sua filha a ajudava a contar as contrações. Teve um parto vaginal sem anestesia e muito tranquilo, com a participação de seu marido a segurando o tempo todo, de uma doula e de uma equipe médica na qual confiava plenamente. Ao contrário da filha mais velha, que amamentou com dificuldade, conseguiu insistir com o filho. Declarou que "amamentar a mãe tem que querer muito", mas teve ajuda da enfermeira obstétrica e, quando eu a conheci, ela ainda amamentava João, já com um ano e meio. Por conta disso, "mãe e filho ficam mais agarrados". Milena cita um livro de uma autora feminista e afirma que a sociedade cobra muito da mulher, que tem que ser uma boa mãe, uma boa funcionária. Fala que procura fazer bem seu trabalho, mas voltar para casa e estar com os filhos se tornaram sua prioridade.

Milena constrói uma narrativa coerente em que sempre houve o desejo pela maternidade, que pareceu guiar momentos anteriores de sua vida. Em sua 
narrativa, a ênfase na articulação dos projetos é clara - desde a escolha da profissão estável à gestação e ao parto, ao modo de vivenciá-los e de criar os filhos depois. ${ }^{\text {Io }}$ Assim como outras mulheres mais jovens entrevistadas, planejar a vida é um comportamento apreciado e valorizado por Milena. Não à toa, Rosa, com 65 anos na época da pesquisa, chamava a geração da filha, amiga de Milena, de "exceliana", por conta do uso constante de planilhas de Excel para organizar a vida. Aqui o contraste com as entrevistadas mais velhas é significativo, pois embora quisessem filhos, a maioria engravidou cedo, logo após o casamento, tendo sido uma surpresa perturbadora, e não se deteve na escolha do obstetra nem do tipo de parto.

Se, nesses aspectos, a narrativa de Milena se aproxima da de outras mulheres jovens entrevistadas, ela explicita tensões nas suas vivências, por conta dos modelos de maternidade, da boa mãe especificamente, que exercem uma "cobrança" na mulher. Ela comentou que, logo no início, se sentia insegura para ter filho, já por se preocupar como mãe, embora sempre tenha desejado isso. Menciona seu medo da dor, de doença, de sangue, bem como a ansiedade com a espera do nascimento, que a levaram a preferir uma cesárea quando de sua primeira gestação. A cesárea depois pareceu não a tornar mãe plenamente, daí a opção pelo parto vaginal na gestação seguinte. Conta as dificuldades em amamentar a filha, que acabou recebendo "complemento" desde cedo, fazendo-a buscar apoio no segundo filho. Comenta depois sobre a conciliação de maternidade e trabalho, declarando que "abriu mão" de fazer carreira e ser promovida para priorizar os filhos. Ou seja, se a maternidade foi sempre um desejo, ela teve vários custos para Milena, ainda que essa dimensão negativa esteja menos enfatizada em sua narrativa.

Ao mesmo tempo em que apontou esses receios e dificuldades, insinua também um movimento para os superar, principalmente na segunda gestação. Milena explicita o quanto essa preparação para o segundo parto foi também uma preparação para ser mãe. Nessa passagem, destaca-se a maternidade como experiência corporal, muito enfatizada por Milena. Ela comenta já na primeira gravidez que soube desde a fecundação. Se a cesárea atendeu aos medos, foi sentida como deixando um "vácuo". O parto humanizado desejado foi considerado uma forma de vivenciar mais intensamente a maternidade. Sentir as dores do parto, a ponto de não tomar anestesia, e também conseguir amamentar eram experiências vistas como, se não necessárias, muito importantes. Essa percepção aparece em outros estudos (Carneiro, 20I5a; Hirsch, 20I5) e vem associada a uma visão crítica da cesárea, caracterizada como cirurgia e não como parto. Trata-se, portanto, de um parto que deve ser vivido de acordo com um modelo - com contrações, sem intervenções - abraçado por Milena com base em suas leituras e em sua escolha por uma obstetra adepta do parto humanizado.

Essa dimensão corporal da maternidade, a ser vivenciada de uma forma específica - no parto vaginal - parece diminuir o sentido de ser mãe de outras 
formas. Embora Milena já tivesse uma filha que a fez se sentir mãe desde a gestação, parecia-lhe que essa vivência ainda não era suficiente. Mesmo lidando com a internação de sua filha aos dez meses por conta de uma infecção, faltava algo. Assim, para uma maternidade plena, era preciso não só pôr de lado seus desconfortos e medos pelos filhos, mas também experimentar esse deslocamento de si no corpo, suportando, em nome deles, as dores do parto e as dificuldades da amamentação. Não pediu anestesia porque, segundo sua médica, poderia afetar o bebê. Ressalto que no relato de Milena não aparece uma fruição do parto, como entre as mulheres estudadas por Carneiro (2015a), nem uma narrativa do trabalho de parto guiada por sensações corporais, como apresentado por Julia e outras mulheres, sugerindo o parto como experiência de si. Seu relato enfatiza sim a percepção de uma vivência física do parto feita em nome do filho. Essa dedicação ao filho expressava o modelo da boa mãe, reconhecido por ela como cobrança externa da sociedade, mas mesmo assim internalizado.

\section{CONSIDERAÇÕES FINAIS}

Em minha pesquisa, tenho buscado entender como as narrativas de parto, ao se deter em certos aspectos e não em outros, mostram o que essas mulheres consideram relevante me contar a respeito de suas experiências. Como Halbwachs (I990) argumenta, a memória é seletiva e sujeita à relação com os outros. A ação do tempo está imbricada a essa relação com os outros durante os acontecimentos, de modo que deles se lembra ou se esquece com maior ou menor intensidade, levando Halbwachs (I990: 5I) a afirmar que "cada memória individual é um ponto de vista sobre a memória coletiva”. Pollak (I992) acrescenta que a memória sofre também flutuações em função do contexto em que está sendo expressa, de forma que sua estruturação é marcada pelas preocupações do momento. Ao se transformar em narrativa, ganha uma forma particular e incorpora significados e valores coletivos (Riesmann, I993; Maynes et al., 2008).

Assim, as narrativas de parto lidam com um evento do passado, do qual se resgatam vivências específicas que são relatadas de formas distintas de acordo com ordens de relevância socialmente compartilhadas. Se o fato de o parto ter ocorrido há alguns ou muitos anos pode afetar o que dele se lembra, para fins de análise, interessa entender o que é rememorado nas histórias e como é contado. Martins (2005) e Almeida (I987) estudaram respectivamente as memórias de mulheres de camadas trabalhadoras e segmentos médios sobre seus partos e comentam como suas narrativas da gestação e do parto são rápidas, com poucos detalhes. Ambas explicam essa forma de narrar não apenas em relação ao tempo já passado, mas atrelada também ao sentido da maternidade para essas mulheres, um papel social a ser desempenhado sem questionamento. De forma semelhante, em outro trabalho (Rezende, 20I7), analiso como as narrativas de parto das mulheres mais jovens são mais elaboradas em 
detalhes, com muitas referências às sensações e emoções, do que as histórias contadas pelas mais velhas. Como Martins e Almeida, interpreto que essa diferença se deve não apenas aos efeitos da memória, mas também ao lugar do parto na vida dessas mulheres, por conta dos sentidos específicos de maternidade para elas.

Para as mulheres mais jovens que entrevistei, a maternidade aparece claramente como projeto conscientemente elaborado (Velho, I98I), em que gestação e parto são objetos de escolhas cuidadosas. A forma de conjugalidade - compartilhada e mais igualitária (Salem, 2007) - e a situação profissional dessas mulheres contribuem para o modo como esse papel social de gênero é abraçado. Acontece dentro de uma relação conjugal estável e em um momento de carreira profissional consolidada, consideradas explicitamente para algumas, como Milena, condições necessárias para criar os filhos. Com maridos que participaram ativamente da gestação e do parto, todas afirmaram dividir com eles o cuidado das crianças, possibilitando desse modo a conciliação do trabalho com a maternidade. As narrativas constroem, portanto, uma trajetória conjugal e profissional planejada de acordo com o desejo da maternidade, refletindo as possibilidades dadas por suas condições socioeconômicas. A coerência apresentada pode ser efeito da narrativa biográfica, como alerta Bourdieu (I 998), mas destaca de todo modo a ênfase atribuída à agência percebida em torno da maternidade.

Se exercer o papel social é uma escolha, existem significados e valores morais que orientam sua vivência. Para essas mulheres, a gestação construía o vínculo de parentesco com o bebê, tornando-o filho antes de nascer, pessoa com nome e sobrenome. Representava, assim, o início de suas experiências como mãe. Diferentemente das mulheres australianas estudadas por Lupton e Schmied (20I3), que relataram com estranheza a hora em que o bebê saía delas, nas histórias que ouvi, era uma criança nomeada que nascia delas, momento em geral descrito com muita emoção.

Nesse sentido, o cuidado do filho começava com o modo de conduzir a gestação e planejar e preparar o parto. Esta forma de vivenciar uma e outro revelava uma acentuação da agência das mulheres (Rezende, 20I5a), que buscavam controlar seus corpos, suas emoções, organizando também seus trabalhos e espaços domésticos para a chegada dos filhos. Essa ênfase narrativa não ignora os limites dados pela medicalização dos corpos, contexto marcado por relações de poder e saberes que atravessam o cuidado de si. Não à toa, em todas as narrativas, sobressai a presença significativa da interação com o obstetra e demais membros da equipe médica no parto, lembrando o quanto as escolhas feitas aconteciam dentro de um campo possível dado pelas relações de poder entre médico e paciente. Como, porém, argumenta Ivry (2010), ao olhar medicalizado e suas práticas se agregam significados culturalmente particulares. Assim, à semelhança das japonesas estudadas por ela, que percebiam os cui- 
dados pré-natais como parte do desempenho da maternidade, vejo no planejamento do parto não só uma forma de controlar riscos e monitorar o corpo feminino, como também um modo de se dedicar ao bebê. A preparação para o parto, com leituras, trabalhos corporais de respiração ou acompanhamento de doulas, constitui um meio de se conectar ao bebê, como afirmaram Julieta e Milena. Se fisicamente o feto está implantado no corpo da mulher, é necessário construir com ele um laço afetivo durante a gestação e, depois, no parto e na amamentação.

Esse processo, segundo os relatos, implicou muitas vezes enfrentar desafios pessoais pelo filho. Aqui apareceu outro sentido de maternidade que envolveu vivenciar corporalmente a relação com o filho - na gestação, ao parir, ao amamentar. Sem isso, a vivência da maternidade apareceu como incompleta. Embora nem todas as mulheres entrevistadas que tiveram cesáreas tenham expressado uma falta ou vazio do modo explícito como Milena o fez, muitas buscaram, mesmo assim, na segunda gravidez, um parto normal, dispostas a pôr de lado seus medos e sentir as dores do trabalho de parto, nem sempre tomando anestesia para as aliviar. Todas amamentaram, o que para algumas foi mais difícil e doloroso do que o parto vaginal.

Enquanto experiência ao mesmo tempo singular e cultural, física e afetiva (Le Breton, 20I3), a dor é um fato, e sua experiência implica os vínculos sociais. Como Carneiro (20I5b) discute, a dor nos relatos de parto pode ter sentidos diversos. Entre as mulheres que ela estuda, a dor física aparece articulada ao sofrimento social, particularmente nas situações em que há procedimentos médicos impostos ou falta de atenção ou cuidado aos desejos da parturiente. Em sua etnografia, há também mulheres que buscam experimentar o parto e suas dores sem anestesia, como forma de "sentir tudo" (Carneiro, 20I5a: I84). Em contraste, no estudo de Salem (2007) sobre os casais grávidos, a dor do parto é considerada negativa e resultado de "distorções socioculturais", como os medos incutidos pelas mães, de modo que, com preparação física e psicológica, seria possível parir sem dor.

Assim, a vivência da dor no parto nos relatos de Julia e Milena, bem como de outras mulheres jovens entrevistadas, pode ser entendida como uma forma de autoconhecimento, daí o destaque dado em suas narrativas a suas sensações corporais no trabalho de parto. Até onde resistem à dor surge também como função das relações sociais presentes. Se a presença de marido e doula reconforta em todos os relatos, a relação com a equipe médica pode ajudar a aguentar as dores, como aconteceu com Milena, ou piorar a experiência, como no caso de Julia. Uma vez que já se sentiam mães, a relação com o filho também afeta a experiência da dor, a ela resistindo pelo bem do bebê. Suportar a dor no corpo pelo filho, como forma de se tornar mãe, pode reforçar o sentido dessa experiência física como rito de passagem (Le Breton, 20I3; Sarti, 200I), expressando também a ideia de amor materno sacrificial presente na ontologia cris- 
tã (Mayblin, 20I I). Mesmo que a maternidade para elas começasse na gestação, ter um trabalho de parto e um parto vaginal e amamentar confirmavam-na de um modo mais ritualizado e marcado. Assim, como Russo (2018) destaca, não era apenas a escolha da maternidade que se tornava uma questão, mas também o modo de a vivenciar.

Nas narrativas de parto analisadas neste artigo, a maternidade se constitui então em uma experiência fortemente corporal, transformando a mulher em mãe e vinculando-a ao bebê/filho. Essa valorização da vivência no corpo remete ao dispositivo de sensibilidade discutido por Duarte (I999), que preconiza o autoaperfeiçoamento contínuo pautado na exploração de sua corporalidade, entendido enquanto domínio sensorial com lógica própria. Constitui assim uma visão de pessoa e uma configuração subjetiva nos termos de Ortner (2007b). Nas histórias examinadas, a gestação acrescida do parto vaginal e da amamentação torna-se experiência corporal que deve ser vivenciada para que se instaure a maternidade. Por meio dessas situações, experimentam-se os limites da dor e sua superação, tanto como forma de autoconhecimento como pelo bem de seus filhos. Ganham assim um valor moral na medida em que se apresentam como vivências necessárias tanto para a construção do vínculo com o filho como para o desempenho adequado do papel de mãe. Tensionam, portanto, a agência dessas mulheres nos seus projetos de maternidade.

Recebido em Io/9/20I8 | Revisado em 29/3/20I9 | Aprovado em 29/4/2019

Claudia Barcellos Rezende é doutora em antropologia pela London School of Economics e professora titular do Departamento de Antropologia da Universidade do Estado do Rio de Janeiro (Uerj). Entre suas publicações estão artigos em coletâneas e periódicos, a organização e apresentação do volume de ensaios Raça como retórica: a construção da diferença, com Yvonne

Maggie, e Cultura e sentimentos: ensaios em antropologia das emoções, com Maria Claudia Coelho, e os livros Os significados da amizade: duas visões de pessoa e sociedade, Retratos do estrangeiro: identidade nacional, subjetividade e emoção e Antropologia das emoções, em coautoria com Maria Claudia Coelho.

Suas áreas de atuação são: amizade e família, subjetividade e emoção, gênero, corpo, gravidez e parto. 


\section{NOTAS}

I Uma primeira versão deste artigo foi apresentada no I 8응 Congresso Mundial da International Union of Anthropological and Ethnological Sciences (IUAES), em Florianópolis, 2018.

2 Os dados pessoais das entrevistadas foram alterados para preservar seu anonimato.

3 Em todas as narrativas, em ambos os grupos etários, o feto era referido como bebê, por isso minha opção por usar esse termo no texto.

4 Os dados analisados aqui resultam dos projetos de pesquisa "Histórias de parto: pessoa e parentesco" e "O parto narrado: corpo, subjetividade e relacionalidade", apoiados pelo Programa Prociência da Uerj e pelo CNPq por meio de Bolsa de Produtividade.

5 Nas entrevistas com mulheres jovens sobre seus partos feitas por um aluno meu, a descrição do parto, mesmo quando cesárea, foi bem mais detalhada do que nos relatos feitos a mim.

6 Carneiro (2015a: I70), contudo, em sua etnografia sobre grupos de preparação para parto mais natural, destaca que a centralidade da experiência do parto, para o qual se prepara ao longo da gestação, ressalta uma busca pela intensidade que nem sempre está associada à maternidade. Algumas de suas interlocutoras gostariam de ter novos partos, mas não mais filhos.

7 Ivry (20I0) apresenta em seu estudo etnográfico da gravidez em Israel e no Japão a maneira como significados culturais atravessam a medicalização do corpo, dando-lhe características específicas em cada sociedade.

8 Diferenciando-se dos casais estudados por Salem (2007), que vivenciavam a gravidez em conjunto.

9 Embora Mayblin (20II) desenvolva seus argumentos em relação a sua etnografia sobre uma cidade no interior nordestino, acredito que essa ontologia cristã permeia outros segmentos sociais na sociedade brasileira.

Io O caráter planejado da gestação - desde a concepção a seus cuidados e às preparações para a chegado do bebê - aparece também em minha pesquisa anterior sobre gravidez (Rezende, 2015a). 


\section{REFERÊNCIAS BIBLIOGRÁFICAS}

Almeida, Maria Isabel Mendes de. (1987). Maternidade: um destino inevitável? Rio de Janeiro: Editora Campus.

Ariès, Philippe. (I98I). História social da criança e da família. 2 ed. Rio de Janeiro: Zahar.

Badinter, Elizabeth. (1985). Um amor conquistado: o mito do amor materno. Rio de Janeiro: Nova Fronteira.

Barros, Myriam Lins de et al. (2009). Mulheres, geração e trabalho. Interseções: Revista de Estudos Interdisciplinares, I I/2, p. 335-35I.

Bourdieu, Pierre. (1998). A ilusão biográfica. In: Amado, Janaina \& Ferreira, Marieta M. (orgs.). Usos e abusos da história oral. Rio de Janeiro: Fundação Getulio Vargas, p. I83-I9I.

Bruner, Edward. (I986). Experience and its expressions. In: Turner, Victor W. \& Bruner, Edward M. (org.). The anthropology of experience. Chicago: University of Chicago Press, p. 3-30.

Cadoná, Eliane \& Strey, Marlene Neves. (20I4). A produção da maternidade nos discursos de incentivo à amamentação. Revista Estudos Feministas, 22/2, p. 477-499. Disponível em <http://dx.doi.org/IO.I590/SoI04-026X20I4000200005 2. Acesso em 29 set. 2014.

Carneiro, Rosamaria Giatti. (2015a). Cenas de parto e políticas do corpo. Rio de Janeiro: Editora Fiocruz.

Carneiro, Rosamaria Giatti. (20I5b). "Para chegar ao Bojador, é preciso ir além da dor": sofrimento no parto e suas potencialidades. Sexualidad, Salud y Sociedad, 20, p. 9I-II2. Disponível em <http://dx.doi.org/ıo.I590/I9846487.sess.2015.20.08.a $\geq$. Acesso em I set. 2018.

Carson, Anna et al. (2017). A narrative analysis of the birth stories of early-age mothers. Sociology of Health \& Illness, 39/6, p. 8I6-83I. Disponível em <https://www.ncbi.nlm. nih.gov/pmc/articles/PMC5516245/ $\geq$. Acesso em 2 abr. 2018. Carsten, Janet. (2004). After kinship. Cambridge: Cambridge University Press.

Carsten, Janet. (2000). Introduction: cultures of relatedness. In: Carsten, Janet (org.). Cultures of relatedness. Cambridge: Cambridge University Press, p. I-37. 
Cussins, Charis M. (I998). Quit sniveling, cryo-baby. We'll work out which one's your mama! In: Davis-Floyd, Robbie \& Dumit, Joseph (orgs.). Cyborg babies: from tecnho-sex to techno-tots. London: Routledge, p. 40-66.

Dias, Camila Manni do Amaral. (2016). "Aqui a gente é tratada como pessoa, no hospital é como corpo": motivações e trajetórias de gestantes em uma Casa de Parto pública no Rio de Janeiro. Dissertação de Mestrado. PPCIS/Universidade do Estado do Rio de Janeiro.

Duarte, Luiz Fernando Dias. (I999). O império dos sentidos: sensibilidade, sensualidade e sexualidade na cultura ocidental moderna. In: Heilborn, Maria Luiza (org.). Sexualidade: o olhar das ciências sociais. Rio de Janeiro: Jorge Zahar, p. 2I-30.

Fonseca, Claudia. (2002). Mãe é uma só? Reflexões em torno de alguns casos brasileiros. Psicologia USP, I3/2, p. 49-68.

Foucault, Michel. (2012). Vigiar e punir. Petrópolis: Vozes.

Freire, Maria Martha de Luna. (2008). "Ser mãe é uma ciência": mulheres, médicos e a construção da maternidade científica na década de I920. História, Ciências, Saúde - Manguinhos, I5, p. I53-I7I. Disponível em: <http://www.scielo. br/scielo.php?script=sci_arttext\&pid=SoI04-5970200 $8000500008 \& \operatorname{lng}=$ en \&nrm=iso $>$. Acesso em 3 jul. 20 I 8.

Halbwachs, Maurice. (I990). A memória coletiva. São Paulo: Vértice.

Hirsch, Olivia. (2015). O parto "natural" e "humanizado" na visão de mulheres de camadas médias e populares no Rio de Janeiro. Civitas, I5/2, p. 229-249.

Ivry, Tsipy. (2010). Embodying culture: pregnancy in Japan and Israel. New Brunswick: Rutgers University Press.

LeBreton, David. (2013). Antropologia da dor. São Paulo: Ed. Unifesp.

Luna, Naara. (2002). Maternidade desnaturada: uma análise da barriga de aluguel e da doação de óvulos. Cadernos Pagu, I9, p. 233-278.

Lupton, Deborah \& Schmied, Virginia. (2013). Splitting bodies/selves: women's concepts of embodiment at the moment of birth. Sociology of Health \& Illness, 35/6, p. 828- 
84I. Disponível em: <dx.doi.org/IO.IIII/j.I467-9566.20I2.0I 532.X>. Acesso em 29 set. 2014.

Machado, Maria das Dores. (2009). Subjetividade feminina nas famílias dos segmentos populares do Rio de Janeiro. Interseções, II/2, p. 307-334.

Martins, Ana Paula Vosne. (2005) Memórias maternas: experiências da maternidade na transição do parto doméstico para o parto hospitalar. História Oral, 8/2, p. 6I-76. Disponível em: <http://revista.historiaoral.org.br/index. php? journal =rho \& page $=$ article \& op $=$ view $\&$ path $\%{ }_{5}$ B $\%$ 5D=I74>. Acesso em 9 mar. 2018.

Mayblin, Maya. (20II). The madness of mothers. Agape love and the maternal myth in Northeast Brazil. American Anthropologist, II4/2, p. 240-252.

Maynes, Mary Jo et al. (2008). Telling stories: the use of personal narratives in the social sciences and history. Ithaca: Cornell University Press.

Ortner, Sherry B. (2007a). Poder e projetos: reflexões sobre a agência. In: Grossi, Miriam et al (orgs.). Conferências e diálogos: saberes e práticas antropológicas. Blumenau: Nova Letra, p. 45-8o. Disponível em: <http://www.abant.org.br/ conteudo/livros/ConferenciaseDialogos.pdf $>$. Acesso em Io maio 2018.

Ortner, Sherry B. (2007b). Subjetividade e crítica cultural. Horizontes Antropológicos, I3/28, p. 375-405. Disponível em:<https://dx.doi.org/IO.I590/SoI04-7I832007000200 oI5>. Acesso em io maio 2018.

Pina-Cabral, João de \& Silva, Vanda Aparecida da. (2013). Gente liure: consideração e pessoa no Baixo Sul da Bahia. São Paulo: Terceiro Nome.

Pollak, Michel. (I992). Memória e identidade social. Estudos Históricos, 5/IO, p. 200-2I 2.

Rabinow, Paul \& Rose, Nikolas. (2006). Biopower today. BioSocieties, I, p. I95-2I7. Disponível em doi:Io.Ior7/ Si7458552060400I4. Acesso em 22 maio 2017.

Ragoné, Helena. (I997). Chasing the blood tie: surrogate mothers, adoptive mothers and fathers. In: Lamphere, Louise; Ragoné, Helena \& Zavella, Patricia (orgs.). Situated lives: gender and culture in everyday life. London: Routledge, p.IIO-I 27. 
Rezende, Claudia Barcellos. (2017). A narrativa como forma de análise da experiência do parto. Trabalho apresentado no Grupo de Trabalho Métodos e Técnicas em Antropologia da Saúde, XII Reunião de Antropologia do Mercosul, Posadas, Argentina.

Rezende, Claudia Barcellos. (20I5a). O parto em contexto: narrativas da gravidez entre gestantes no Rio de Janeiro. Civitas, I5/2, p. 2I4-228. Disponível em: <http://dx.doi.org/ıo. I5448/I984-7289.20I5.2.18947>. Acesso em Io maio 2018.

Rezende, Claudia Barcellos. (20I5b). Nomes que (des)conectam: gravidez e parentesco no Rio de Janeiro. Mana, 2I/3, p. 587-607.

Riessman, Catherine Kohler. (1993). Narrative analisys. London: Sage Publications.

Russo, Jane. (2018). Padecendo no paraíso: dor, sofrimento e prazer no ideário do parto humanizado. Trabalho apresentado no I 8 Congresso Mundial da IUAES, Florianópolis. Salem, Tania (2007). O casal grávido: disposições e dilemas da parceria igualitária. Rio de Janeiro: Ed. FGV.

Salem, Tania. (I980). Mulheres faveladas: "com a venda nos olhos". In: Cavalcanti, Maria Laura et al. (orgs). Perspectivas antropológicas da mulher I. Rio de Janeiro: Zahar editores, p. 49-99.

Sarti, Cynthia A. (200I). A dor, o indivíduo e a cultura. Saúde e Sociedade, Io/I, p. 3-13.

Scavone, Lucila. (200I). Maternidade: transformações na família e nas relações de gênero. Interface, 5/8, p. 47-60. Disponível em: <http://dx.doi.org/IO.I590/SI4I4-3283200 I000100004>. Acesso em 20 jun. 2017.

Tornquist, Carmem Susana. (2002). Armadilhas da Nova Era: natureza e maternidade no ideário da humanização do parto. Revista Estudos Feministas, Io, p. 483-492. Disponível em: <http://dx.doi.org/IO.I590/SoI04-026X20020 002 ooor6>. Acesso em I5 maio 2018.

Velho, Gilberto. (I98I). Individualismo e cultura: notas para uma antropologia da sociedade contemporânea. Rio de Janeiro: Zahar.

Viegas, Susana de Matos. (2007). Terra Calada: os Tupinambás na Mata Atlântica do Sul da Bahia. Rio de Janeiro: 7Letras. 


\section{SENTIDOS DA MATERNIDADE EM NARRATIVAS DE PARTO NO RIO DE JANEIRO}

Resumo

Neste artigo, analiso os sentidos de maternidade presentes em narrativas do parto de mulheres brancas heterossexuais de camadas médias do Rio de Janeiro, com idades entre 37 e 46 anos. Sobressai o investimento afetivo no planejamento do parto, muitos deles realizados a partir de uma perspectiva médica humanizada, reforçando uma visão da maternidade como projeto construído a partir de um campo de possibilidades dado por suas situações socioeconômicas, formas de conjugalidade e valores morais. O modo como o feto enquanto bebê figura nas narrativas aponta para concepções sobre o vínculo entre mãe e filho, construído e reforçado a partir de uma experiência corporal da gestação e do parto considerada necessária. Partindo dos conceitos de Velho e Ortner sobre projeto, agência e subjetividade, discuto como uma configuração subjetiva que valoriza especialmente a corporalidade da maternidade pode tensionar a agência dessas mulheres.

\section{THE MEANINGS OF MOTHERHOOD IN CHILDBIRTH NARRATIVES IN RIO DE JANEIRO} rations comes to the fore, with many of the births involv ing a humanized birth, reinforcing the idea of motherhood as a female project affected by the socioeconomic situations, forms of conjugality, and moral values of the women involved. How the baby figures in the narratives is also revealing of conceptions surrounding the bonds between mother and child, built and reinforced by a bodily experience of pregnancy and birth that is seen as necessary. Based on the concepts of Velho and Ortner of project, agency and subjectivity, I argue that a subjective formation that especially values an embodied motherhood can reveal the dynamic tensions involved in these women's agency.
Palavras-chave

Parto;

narrativas;

maternidade;

corpo;

camadas médias.
Keywords

Birth; narratives; motherhood; body; middle class. 